Article

\title{
Association of Bovine Leukemia Virus-Induced Lymphoma with BoLA-DRB3 Polymorphisms at DNA, Amino Acid, and Binding Pocket Property Levels
}

\author{
Chieh-Wen Lo ${ }^{1,2}$, Shin-nosuke Takeshima ${ }^{3,4}{ }^{\mathbb{D}}$, Kosuke Okada ${ }^{5}$, Etsuko Saitou ${ }^{6}$, Tatsuo Fujita ${ }^{7}$, \\ Yasunobu Matsumoto ${ }^{1,2}$, Satoshi Wada ${ }^{8}$, Hidetoshi Inoko ${ }^{9}$ and Yoko Aida ${ }^{1,2,3,10, *}$
}

check for updates

Citation: Lo, C.-W.; Takeshima, S.-n.; Okada, K.; Saitou, E.; Fujita, T.; Matsumoto, Y.; Wada, S.; Inoko, H.; Aida, Y. Association of Bovine Leukemia Virus-Induced Lymphoma with BoLA-DRB3 Polymorphisms at DNA, Amino Acid, and Binding Pocket Property Levels. Pathogens 2021, 10, 437. https://doi.org/ 10.3390 / pathogens10040437

Academic Editor: Sante Roperto

Received: 12 March 2021

Accepted: 2 April 2021

Published: 6 April 2021

Publisher's Note: MDPI stays neutral with regard to jurisdictional claims in published maps and institutional affiliations.

Copyright: (c) 2021 by the authors. Licensee MDPI, Basel, Switzerland This article is an open access article distributed under the terms and conditions of the Creative Commons Attribution (CC BY) license (https:// creativecommons.org/licenses/by/ $4.0 /)$
1 Laboratory of Global Animal Resource Science, Graduate School of Agricultural and Life Sciences, The University of Tokyo, 1-1-1 Yayoi, Bunkyo-ku, Tokyo 113-8657, Japan; rogerwen80@gmail.com (C.-W.L.); matsumoto-yasu@mvi.biglobe.ne.jp (Y.M.)

2 Laboratory of Global Infectious Diseases Control Science, Graduate School of Agricultural and Life Sciences, The University of Tokyo, 1-1-1 Yayoi, Bunkyo-ku, Tokyo 113-8657, Japan

3 Viral Infectious Diseases Unit, RIKEN, 2-1 Hirosawa, Wako, Saitama 351-0198, Japan; takesima@jumonji-u.ac.jp

4 Department of Food and Nutrition, Jumonji University, Niiza, Saitama 352-8510, Japan

5 Iwate University, 7-360 Mukai-shinden Ukai, Takizawa, Iwate 020-0667, Japan; kosuke@iwate-u.ac.jp

6 Hyogo Prefectural Awaji Meat Inspection Center, 49-18 Shitoorinagata, Minamiawaji, Hyogo 656-0152, Japan; Etsuko_Saitou@pref.hyogo.lg.jp

7 Livestock Research Institute of Oita Prefectural Agriculture, Forestry and Fisheries, Research Center, Kuju, Taketa, Oita 878-0201, Japan; pu1508708@pref.oita.jp

8 Photonics Control Technology Team, RIKEN Center for Advanced Photonics, Wako 351-0198, Japan; swada@riken.jp

9 Genome Analysis Division, GenoDive Pharma Inc., 4-14-1 Nakamachi, Atsugi-shi, Kanagawa 243-0018, Japan hinoko@is.icc.u-tokai.ac.jp

10 Benno Laboratory, Baton Zone Program, RIKEN Cluster for Science, Technology and Innovation Hub, 2-1 Hirosawa, Wako, Saitama 351-0198, Japan

* Correspondence: aida@riken.jp

Abstract: Bovine leukemia virus (BLV) causes enzootic bovine leucosis, a malignant B-cell lymphoma in cattle. The DNA sequence polymorphisms of bovine leukocyte antigen (BoLA)-DRB3 have exhibited a correlation with BLV-induced lymphoma in Holstein cows. However, the association may vary between different cattle breeds. Furthermore, little is known about the relationship between BLV-induced lymphoma and DRB3 at the amino acid and structural diversity levels. Here, we comprehensively analyzed the correlation between BLV-induced lymphoma and DRB3 at DNA, amino acid, and binding pocket property levels, using $106 \mathrm{BLV}$-infected asymptomatic and 227 BLV-induced lymphoma Japanese black cattle samples. DRB3*011:01 was identified as a resistance allele, whereas $D R B 3^{*} 005: 02$ and $D R B 3^{*} 016: 01$ were susceptibility alleles. Amino acid association studies showed that positions $9,11,13,26,30,47,57,70,71,74,78$, and 86 were associated with lymphoma susceptibility. Structure and electrostatic charge modeling further indicated that binding pocket 9 of resistance DRB3 was positively charged. In contrast, alleles susceptible to lymphoma were neutrally charged. Altogether, this is the first association study of BoLA-DRB3 polymorphisms with BLV-induced lymphoma in Japanese black cattle. In addition, our results further contribute to understanding the mechanisms regarding how $B o L A-D R B 3$ polymorphisms mediate susceptibility to BLV-induced lymphoma.

Keywords: bovine leukemia virus; lymphoma; BoLA-DRB3; polymorphisms; antigen recognition sites; amino acid motif; peptide-binding pockets; electrostatic charge; association study

\section{Introduction}

Enzootic bovine leucosis (EBL) is a lymphoproliferative disease characterized by B-cell lymphoma and is the most common neoplasm disease in cattle [1]. Bovine leukemia virus 
(BLV) infection is the causative agent of EBL [2]. As EBL is a lethal disease leading to severe financial burden in the cattle industry, it is recognized by the World Organization for Animal Health as a disease of importance for international trade [3]. Recent surveys in most countries worldwide except Europe have reported a continuous increase in BLV infection in cattle [4]. Consequently, it is difficult to develop new strategies to decrease the disease prevalence rate, as the mechanisms of BLV-induced lymphoma are unknown.

BLV belongs to family Retroviridae and genus Deltaretrovirus and is closely related to the human T-cell leukemia viruses [5]. Like other retroviruses, the DNA copies of BLV RNA genome integrate into the host genome as a provirus and induce lifelong infection. In the majority of cases, approximately $70 \%$ of BLV-infected cattle are asymptomatic carriers. Approximately $30 \%$ of infected individuals progress to persistent lymphocytosis, characterized by polyclonal expression of the non-neoplastic $\mathrm{CD} 5^{+} \mathrm{B}$ lymphocyte population. Only $1-5 \%$ of infections develop B-cell lymphoma after a prolonged latency period [6]. The low mortality rate of BLV infection implies that the virus itself may not be sufficient to induce disease onset and that host genetic polymorphisms in individuals potentially play a key role in disease susceptibility.

The major histocompatibility complex (MHC) is a highly polymorphic gene set responsible for peptide antigen presentation and immune responsiveness and is, therefore, associated with disease susceptibility [7]. Bovine leukocyte antigen (BoLA) is the MHC system in cattle [8]. Specifically, BoLA-DRB3 is the highly polymorphic BoLA class II locus, with 365 alleles registered in the Immuno-Polymorphism Database (IPD)-MHC database (https://www.ebi.ac.uk/ipd/mhc/group/BoLA/) (accessed on 4 April 2021) and is associated with many infectious diseases in cattle [9-11]. The associations of BoLA-DRB3 polymorphisms with BLV pro-viral load (PVL) and related symptoms are well documented [12-14]. In fact, BoLA-DRB3 polymorphisms have been shown to affect BLV PVL regulation in a cattle experimental infection model $[15,16]$, thereby strengthening the importance of BoLA-DRB3 in BLV transmission and disease progression. Indeed, BoLA-DRB3 is a promising target for breeding selection to decrease BLV transmission and related pathogenesis $[17,18]$. However, we recently found that BLV PVL and lymphoma are associated with differential BoLA-DRB3 polymorphisms in Holstein cows [19], and thus, further research regarding the effect of $B o L A-D R B 3$ polymorphisms on lymphoma development is warranted. In addition, the associations between BoLA-DRB3 polymorphisms and BLV-related diseases vary in different breeds and locations of cows. However, information regarding the association between BoLA-DRB3 polymorphisms and BLV-induced lymphoma is currently only available in Holstein cows, and therefore the relationship requires elucidation in different breeds of cattle, for example, Japanese black cattle.

A functional BoLA class II DR molecule consists of an $\alpha$ chain and a $\beta$ chain, that are encoded from a single polymorphic gene, $B o L A-D R A$, and a highly polymorphic gene, BoLA-DRB3, respectively. Therefore, the antigen peptide-binding preference of BoLA class II DR molecule is mainly determined by the BoLA-DR $\beta$ polymorphisms. The polymorphisms of BoLA-DRB3 occur in the exon 2 region, encoding the BoLA-DR $\beta \beta 1$ domain, which is the peptide-binding cleft, containing five peptide-binding pockets, 1, 4, 6, 7 , and 9 , which constitute the structure and govern the binding strength of peptides with BoLA-DR $\beta$ [20]. Consequently, the amino acid composition and the chemical/physical property variations of these five binding pockets may largely affect disease susceptibility. It is known that the binding affinity of peptide antigen with MHC class II is one of the factors that determine subsequent $\mathrm{T}$ helper cell-mediated immune responses, i.e., $\mathrm{T}$ helper type 1 (Th1) and Thelper type 2 (Th2) responses [21]. Th1 is known for cell-mediated immunity, secreting interferon- $\gamma($ IFN- $\gamma)$, and efficacy against viruses [22,23]. Furthermore, a recent study indicated that a toll-like receptor 7 agonist could activate bovine Th1 and thus promoted anti-BLV infection in vivo [24]. Th2 is associated with humoral immunity, which is known to be less effective against BLV infection [25]. Indeed, experimental infection in an ovine model demonstrated that amino acids 70 and 71 in the binding pocket 4 of ovine leukocyte antigen (OLA)-DR $\beta$ were critical for BLV-induced lymphoma susceptibility 
or resistance by affecting the efficiency of Th1 activation [26,27]. This result highlights the importance of amino acid and structure analysis of BoLA-DR $\beta$ in understanding how BoLA-DR $\beta$ polymorphisms affect lymphoma susceptibility. In addition, it is known that differences in the binding pockets property of MHC molecules affect the peptide binding preference. For example, HLA-DQ2 molecules with positively charged binding pockets compared with that with negatively charged binding pockets has better ability at binding with proline-glutamate rich peptide [28]. Therefore, the study of BoLA-DR $\beta$ polymorphisms at amino acid and structural levels could contribute to understanding the binding pocket properties of each BoLA-DR $\beta$ molecule and potentially provide information for future peptide vaccine development, e.g., the charge of peptide should be taken into account. Although few reports have found an association between the BoLA-DRB3 allele and BLV-induced lymphoma [19,29], little is known about the relationship between BLVinduced lymphoma and BoLA-DR $\beta$ at the amino acid and structure levels. Here, we present the first association study involving BLV-induced lymphoma and BoLA-DRB3 in Japanese black cattle. In addition, the relationship was comprehensively investigated at the BoLA-DRB3 DNA sequence, DR $\beta$ amino acid, and DR $\beta$ binding pocket structural property levels.

\section{Results}

\subsection{BoLA-DRB3 Genotyping in Asymptomatic and Lymphoma Cattle}

Lymphoma cattle blood samples were collected from 227 BLV-infected, disease onset Japanese black cattle. The genotyping was performed in all cattle samples using a PCRsequence-based typing (SBT) method of BoLA-DRB3 at exon 2. In total, 21 known alleles were identified in asymptomatic cattle and 24 known alleles were found in lymphoma cattle (Table 1).

Table 1. Association of the BoLA-DRB3 allele with Bovine leukemia virus (BLV)-induced lymphoma.

\begin{tabular}{|c|c|c|c|c|c|c|}
\hline Allele & $\begin{array}{l}\text { Asymptomatic } \\
\quad(\mathrm{n} .=212)^{1}\end{array}$ & $\begin{array}{l}\text { Lymphoma } \\
\text { (n. = 454) }\end{array}$ & $\mathrm{OR}^{2}$ & $95 \% \mathrm{CI}^{3}$ & $p$-Value & Susceptibility ${ }^{4}$ \\
\hline *001:01 & 9 & 8 & 0.405 & $0.154-1.064$ & 0.0677 & - \\
\hline *002:01 & 18 & 17 & 0.419 & $0.212-0.831$ & 0.0147 & $(\mathrm{R})^{5}$ \\
\hline *004:01 & 0 & 1 & 1.406 & $0.057-34.653$ & 1 & - \\
\hline *005:01 & 1 & 1 & 0.466 & $0.029-7.483$ & 0.5356 & - \\
\hline$* 005: 02$ & 1 & 23 & 11.260 & $1.510-83.945$ & 0.0014 & $S$ \\
\hline$* 005: 03$ & 3 & 31 & 5.106 & $1.543-16.894$ & 0.0021 & $(\mathrm{~S})$ \\
\hline$* 005: 04$ & 2 & 1 & 0.232 & $0.021-2.571$ & 0.2391 & - \\
\hline *005:08 & 0 & 3 & 3.295 & $0.169-64.072$ & 0.5552 & - \\
\hline *006:01 & 1 & 2 & 0.934 & $0.084-10.354$ & 1 & - \\
\hline *007:01 & 7 & 5 & 0.326 & $0.102-1.040$ & 0.0606 & - \\
\hline *008:01 & 1 & 4 & 1.876 & $0.208-16.884$ & 1 & - \\
\hline *009:02 & 7 & 2 & 0.130 & $0.027-0.629$ & 0.0059 & (R) \\
\hline *010:01 & 27 & 45 & 0.754 & $0.454-1.253$ & 0.2855 & - \\
\hline *011:01 & 29 & 13 & 0.186 & $0.095-0.366$ & $<0.00001$ & $\mathrm{R}$ \\
\hline *012:01 & 8 & 20 & 1.175 & $0.509-2.713$ & 0.8369 & - \\
\hline *013:01 & 1 & 1 & 0.466 & $0.029-7.483$ & 0.5356 & - \\
\hline *013:02 & 13 & 20 & 0.705 & $0.344-1.447$ & 0.3426 & - \\
\hline *014:01:01 & 7 & 11 & 0.727 & $0.278-1.903$ & 0.6086 & - \\
\hline *015:01 & 29 & 34 & 0.511 & $0.302-0.864$ & 0.0024 & (R) \\
\hline *016:01 & 44 & 198 & 2.953 & $2.019-4.319$ & $<0.00001$ & $\mathrm{~S}$ \\
\hline${ }^{*} 027: 03$ & 2 & 0 & 0.093 & $0.004-1.938$ & 0.1010 & - \\
\hline *020:01:02 & 1 & 4 & 1.876 & $0.208-16.884$ & 1 & - \\
\hline${ }^{*} 034: 01$ & 1 & 3 & 1.404 & $0.145-13.573$ & 1 & - \\
\hline *038:01 & 0 & 3 & 3.295 & $0.169-64.072$ & 0.5552 & - \\
\hline *044:01 & 0 & 4 & 4.245 & $0.228-79.214$ & 0.3126 & - \\
\hline
\end{tabular}

${ }^{*}$ indicates the allele; ${ }^{1}$ n.: total allele number (= cattle number multiplied by 2$) ;{ }^{2}$ OR: Odds ratio; ${ }^{3} 95 \%$ CI: $95 \%$ confidence intervals;

${ }^{4}$ Susceptibility: $\mathrm{R}=$ resistance; $\mathrm{S}=$ susceptibility after Bonferroni correction; ${ }^{5}$ ( ): significant only before Bonferroni correction. 


\subsection{Association Study of BoLA-DRB3 with BLV-Induced Lymphoma}

An association analysis based on Fisher's exact test found that $D R B 3^{*} 005: 02(\mathrm{OR}=11.260)$ and $D R B 3^{*} 016: 01(\mathrm{OR}=2.953)$ were lymphoma susceptibility alleles, whereas $D R B 3^{*} 011: 01$ $(\mathrm{OR}=0.186)$ was a lymphoma resistance allele (Table 1$)$. In addition, DRB3*005:03 $(\mathrm{OR}=5.106)$ showed a tendency to lymphoma susceptibility, whereas $D R B 3^{*} 002: 01$ $(\mathrm{OR}=0.419), D R B 3^{*} 009: 02(\mathrm{OR}=0.130)$, and $D R B 3^{*} 015: 01(\mathrm{OR}=0.511)$ showed a tendency to lymphoma resistance, although they did not meet the significance threshold after the stringent adjustment for multiple testing (Bonferroni correction).

It was found that the effect of the resistance allele was dominant over the susceptibility allele in PVL association studies [13]. To address whether this observation was true for lymphoma association, we then performed an association study involving the BoLA-DRB3 genotype with BLV-induced lymphoma (Table 2). Interestingly, only the $D R B 3^{*} 016: 01 /{ }^{*} 016: 01$ homozygote $(\mathrm{OR}=7.020)$ was found as a susceptibility genotype, but no resistant genotypes were found after Bonferroni correction. This may be due to the high divergent level of BoLA-DRB3 genotypes, but lacked major resistance genotypes. The susceptibility tendency was found in $D R B 3^{*} 005: 02{ }^{*} 016: 01(\mathrm{OR}=13.405)$ and DRB3*005:03/*016:01 (OR $=10.283)$, whereas resistance tendency was found in $D R B 3^{*} 002: 01 /$ ${ }^{*} 010: 01(\mathrm{OR}=0.180), D R B 3^{*} 002: 01 /{ }^{*} 011: 01(\mathrm{OR}=0.041), D R B 3^{*} 011: 01{ }^{*} 015: 01(\mathrm{OR}=0.050)$, and $D R B 3^{*} 011: 01 /{ }^{*} 016: 01(\mathrm{OR}=0.254)$.

Table 2. Association of BoLA-DRB3 genotype with BLV-induced lymphoma.

\begin{tabular}{|c|c|c|c|c|c|c|}
\hline Genotype ${ }^{1}$ & $\begin{array}{l}\text { Asymptomatic } \\
(\text { n. }=106)^{2}\end{array}$ & $\begin{array}{l}\text { Lymphoma } \\
\text { (n. = 227) }\end{array}$ & $\mathrm{OR}^{3}$ & $95 \% \mathrm{CI}^{4}$ & $p$-Value & Susceptibility 5 \\
\hline${ }^{*} 001: 01 /{ }^{*} 016: 01$ & 2 & 3 & 0.696 & $0.115-4.231$ & 0.6551 & - \\
\hline${ }^{*} 002: 01 /{ }^{*} 005: 03$ & 1 & 3 & 1.406 & $0.145-13.681$ & 1 & - \\
\hline${ }^{*} 002: 01 /{ }^{*} 010: 01$ & 5 & 2 & 0.180 & $0.034-0.941$ & 0.0356 & $(\mathrm{R})^{6}$ \\
\hline${ }^{*} 002: 01 /{ }^{*} 011: 01$ & 5 & 0 & 0.041 & $0.002-0.741$ & 0.0031 & (R) \\
\hline${ }^{*} 002: 01 /{ }^{*} 016: 01$ & 1 & 7 & 3.341 & $0.406-27.507$ & 0.4438 & - \\
\hline${ }^{*} 005: 02 /{ }^{*} 016: 01$ & 0 & 13 & 13.405 & $0.789-227.680$ & 0.0115 & $(S)$ \\
\hline${ }^{*} 005: 03 /{ }^{*} 012: 01$ & 0 & 4 & 4.289 & $0.229-80.387$ & 0.311 & - \\
\hline${ }^{*} 005: 03 /{ }^{*} 016: 01$ & 0 & 10 & 10.283 & $0.597-177.152$ & 0.0341 & $(\mathrm{~S})$ \\
\hline${ }^{*} 010: 01 /{ }^{*} 010: 01$ & 2 & 3 & 0.696 & $0.117-4.312$ & 0.6551 & - \\
\hline${ }^{*} 010: 01 /{ }^{*} 011: 01$ & 3 & 3 & 0.460 & $0.091-2.317$ & 0.3873 & - \\
\hline${ }^{*} 010: 01 /{ }^{*} 015: 01$ & 3 & 4 & 0.616 & $0.135-2.802$ & 0.6837 & - \\
\hline *010:01/*016:01 & 7 & 19 & 1.292 & $0.526-3.175$ & 0.6654 & - \\
\hline${ }^{*} 011: 01 /{ }^{*} 015: 01$ & 4 & 0 & 0.050 & $0.003-0.939$ & 0.0099 & $(\mathrm{R})$ \\
\hline${ }^{*} 011: 01 /{ }^{*} 016: 01$ & 7 & 4 & 0.254 & $0.073-0.886$ & 0.0415 & (R) \\
\hline${ }^{*} 012: 01 /{ }^{*} 015: 01$ & 2 & 3 & 0.696 & $0.115-4.231$ & 0.6551 & - \\
\hline${ }^{*} 012: 01 /{ }^{*} 016: 01$ & 0 & 5 & 5.265 & $0.289-96.103$ & 0.1822 & - \\
\hline${ }^{*} 013: 02 /{ }^{*} 016: 01$ & 3 & 10 & 1.582 & $0.426-5.872$ & 0.7621 & - \\
\hline${ }^{*} 015: 01 /{ }^{*} 016: 01$ & 10 & 15 & 0.679 & $0.295-1.567$ & 0.3769 & - \\
\hline${ }^{*} 016: 01 /{ }^{*} 016: 01$ & 4 & 49 & 7.020 & $2.462-20.017$ & $<0.00001$ & $S$ \\
\hline${ }^{*} 016: 01 /{ }^{*} 020: 01: 02$ & 1 & 3 & 1.406 & $0.145-13.681$ & 1 & - \\
\hline
\end{tabular}

${ }^{*}$ indicates the genotype; ${ }^{1}$ Only genotypes with frequency $>1$ are shown; ${ }^{2}$ n.: total genotype number; ${ }^{3}$ OR, Odds ratio; ${ }^{4} 95 \%$ CI: $95 \%$ confidence intervals; ${ }^{5}$ Susceptibility, $\mathrm{R}=$ resistance, $\mathrm{S}=$ susceptibility after Bonferroni correction; ${ }^{6}$ ( ), significant only before Bonferroni correction.

\subsection{Association Study of BoLA-DR $\beta$ with BLV-Induced Lymphoma at the Amino Acid Level}

The potential mechanisms of allele differential susceptibility in lymphoma are due to variations in antigen recognition sites for their encoding BoLA-DR $\beta$ molecules. The sequence of BoLA-DRB3 at exon 2 allowed us to determine the amino acid variations of 17 antigen recognition sites (positions 9, 11, 13, 26, 28, 30, 37, 47, 57, 61, 67, 70, 71, 74, 78, 85 , and 86), which are located within the five peptide-binding pocket regions of BoLADR $\beta[30,31]$. Through amino acid alignment from all BoLA-DRB3 types identified in this study, we found four $(9,47,78$, and 85$)$ out of 17 positions with biallelic polymorphisms, and the remaining 13 positions accommodate more than two amino acid variants (Figure 1A). 
An association study between antigen recognition sites in peptide-binding pockets with BLV-induced lymphoma indicated that $\mathrm{Q}^{9}, \mathrm{G}^{13}, \mathrm{~L}^{26}, \mathrm{H}^{30}, \mathrm{~F}^{47}, \mathrm{~S}^{57}, \mathrm{R}^{70}, \mathrm{R}^{71}, \mathrm{E}^{74}, \mathrm{~V}^{78}$, and $\mathrm{V}^{86}$ were resistance amino acids (OR ranging from $0.201-0.554$ ); in contrast, $\mathrm{E}^{9}, \mathrm{~T}^{11}, \mathrm{~K}^{13}$, $\mathrm{Y}^{30}, \mathrm{Y}^{47}, \mathrm{D}^{57}, \mathrm{E}^{70}, \mathrm{~K}^{71}, \mathrm{~A}^{74}, \mathrm{Y}^{78}$, and $\mathrm{G}^{86}$ were associated with lymphoma susceptibility (OR ranging from 1.832-3.665) (Figure 1B, only statistically significant amino acids are shown).

A

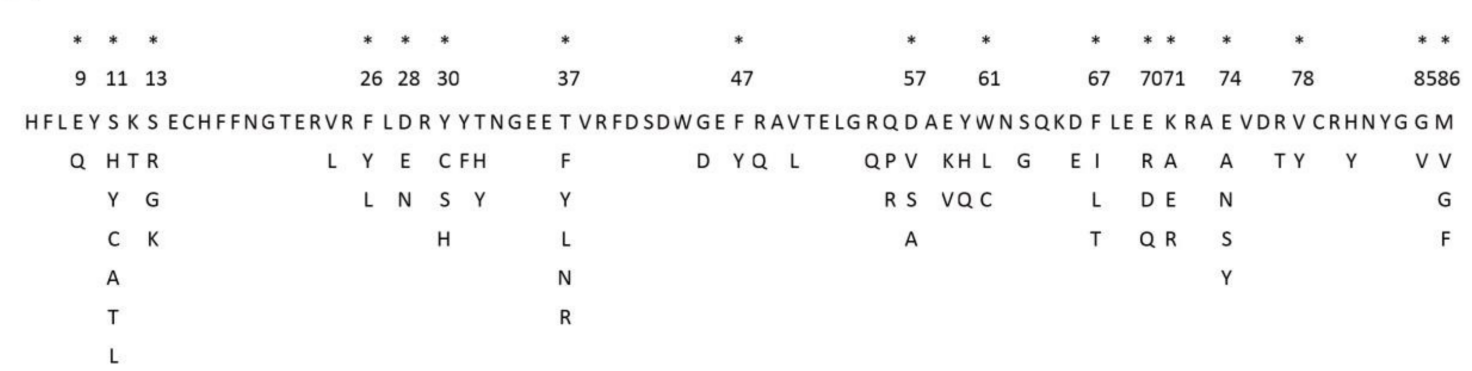

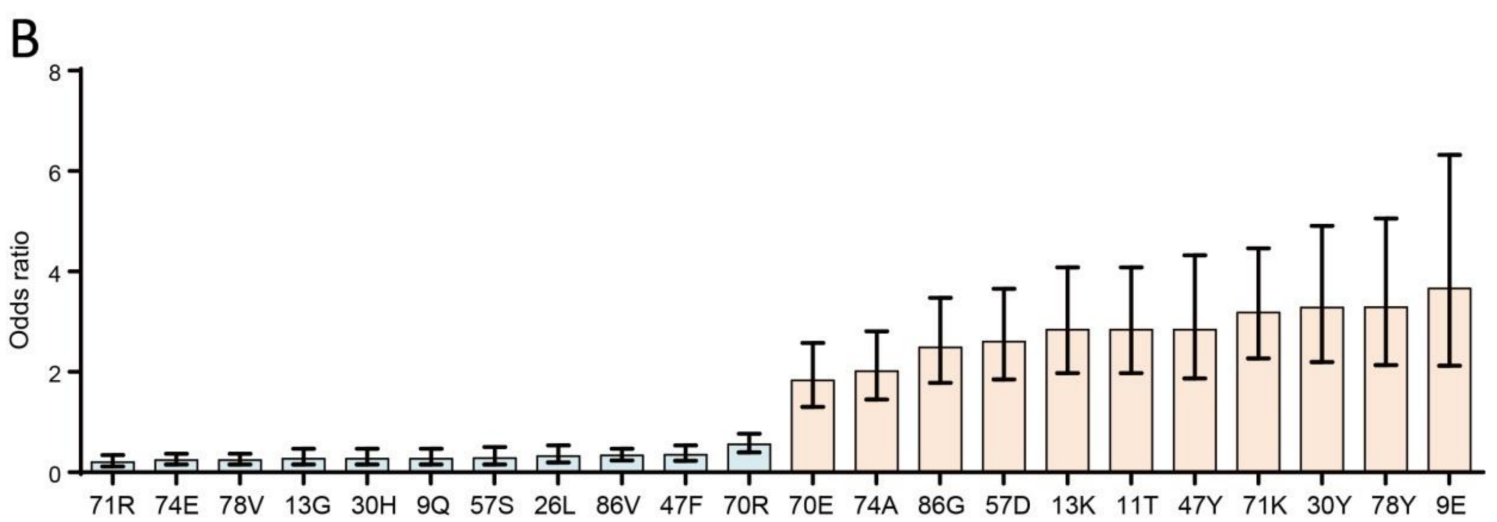

Figure 1. Association of antigen recognition sites of peptide-binding pockets in BoLA-DR $\beta$ with lymphoma. (A) Amino acid diversities of BoLA-DR $\beta$ based on the BoLA-DRB3 allele, which was identified in this study. The asterisks indicate the antigen recognition sites of BoLA-DR $\beta$, located in the antigen interacting position. (B) Odds ratio of BoLA-DR $\beta$ binding pocket amino acids and lymphoma. Resistance amino acid: Odds ratio < 1, indicated in blue; Susceptibility amino acids: Odds ratio $>1$, indicated in red. The association study was performed using Fisher's exact test followed by Bonferroni correction. Error bars indicate the 95\% confidence intervals. Only Bonferroni-corrected significant amino acids are shown.

The MHC bound peptide is determined by the properties of MHC-binding pockets, which are constituted by multiple antigen recognition sites. Therefore, it is important to note the association at the amino acid motif level. We further analyzed the effect of amino acid motifs, which included antigen recognition sites of the BoLA-DR $\beta$ chain. We observed that amino acid residues (Figure 1B), encoded by BoLA-DRB3 in the potential resistance allele group (14 alleles, $\mathrm{OR}<1$, indicated in blue) or susceptibility allele group (11 alleles, OR $>1$, indicated in red), were aligned (Figure 2A). Interestingly, the motifs associated with BLV-induced lymphoma were found in all BoLA-DR $\beta$ pockets-1, 4, 6, 7, and 9 (Figure 2B, only significant motifs are shown). In pocket 4 , amino acid motifs 13 , $26,71,74$, and 78 were found to associate with lymphoma susceptibility. The motif $\mathrm{K}^{13} \mathrm{~F}^{26}$ and $\mathrm{K}^{71} \mathrm{~A}^{74} \mathrm{Y}^{78}$ were susceptible to lymphoma (OR $=2.84$ and 2.95 , respectively), whereas $\mathrm{G}^{13} \mathrm{~L}^{26}$ and $\mathrm{R}^{71} \mathrm{E}^{74} \mathrm{~V}^{78}$ represented resistance motifs ( $\mathrm{OR}=0.273$ and 0.171 , respectively). In addition, the combination of amino acid 86 , found in pocket 1 , with amino acid 70 or motif 71,78 of pocket 4 was associated with lymphoma susceptibility $\left(\mathrm{E}^{70} \mathrm{G}^{86}, \mathrm{OR}=2.36\right.$; $\mathrm{Y}^{71} \mathrm{G}^{78} \mathrm{G}^{86}, \mathrm{OR}=3.52$ ). In contrast, $\mathrm{R}^{70} \mathrm{~V}^{86}$ and $\mathrm{R}^{70} \mathrm{~V}^{71} \mathrm{~V}^{78}$ represented the resistance amino acid combinations ( $\mathrm{OR}=0.329$ and 0.202 , respectively). In pocket 6 , amino acid motifs 11 and 30 showed susceptibility to lymphoma. $\mathrm{T}^{11} \mathrm{Y}^{30}$ was found to be a susceptibility motif $(\mathrm{OR}=2.842)$ and $\mathrm{H}^{11} \mathrm{H}^{30}$ represented a resistance motif $(\mathrm{OR}=0.273)$. For pocket 7 , the relationship was found in motifs 47 and $71 . \mathrm{Y}^{47} \mathrm{~K}^{71}$ was identified as a susceptibility 
motif $(\mathrm{OR}=3.696)$, whereas $\mathrm{F}^{47} \mathrm{R}^{71}$ was a resistance motif $(\mathrm{OR}=0.226)$. In pocket 9 , a motif at positions 9 and 57 was identified. $\mathrm{E}^{9} \mathrm{D}^{57}$ was found to be susceptible to lymphoma $(\mathrm{OR}=2.601)$, whereas $\mathrm{Q}^{9} \mathrm{~S}^{57}$ was resistant to lymphoma $(\mathrm{OR}=0.186)$.

A

\begin{tabular}{|c|c|c|c|c|c|c|c|c|c|c|c|c|c|c|c|c|c|c|c|}
\hline BoLA-DRB3 & 9 & 11 & 13 & 24 & 26 & 30 & 32 & 45 & 47 & 55 & 57 & 59 & 70 & 71 & 74 & 77 & 78 & 86 & OR \\
\hline${ }^{*} 027: 03$ & $E$ & $\mathrm{Y}$ & $\mathrm{R}$ & $\mathrm{V}$ & $\mathrm{F}$ & $\mathrm{C}$ & $\mathrm{Y}$ & $\mathrm{G}$ & $\mathrm{F}$ & Q & $\mathrm{D}$ & $E$ & $E$ & $\mathrm{R}$ & $E$ & $T$ & $\mathrm{~V}$ & G & \multirow{14}{*}{$<1$} \\
\hline *009:02 & $E$ & $S$ & $S$ & V & $\mathrm{F}$ & S & $\mathrm{H}$ & G & $Y$ & Q & D & $E$ & E & $\mathrm{R}$ & $E$ & $\mathrm{~T}$ & V & G & \\
\hline *011:01 & Q & $\mathrm{H}$ & G & V & L & $\mathrm{H}$ & $\mathrm{H}$ & G & $F$ & Q & S & $E$ & $\mathrm{R}$ & $\mathrm{R}$ & $E$ & $\mathrm{~T}$ & V & V & \\
\hline${ }^{*} 005: 04$ & $E$ & $Y$ & $S$ & L & Y & Y & Y & G & $Y$ & $\mathrm{R}$ & D & $\mathrm{K}$ & R & $\mathrm{K}$ & $\mathrm{N}$ & $T$ & $Y$ & $F$ & \\
\hline${ }^{*} 007: 01$ & $E$ & C & $\mathrm{R}$ & V & $F$ & C & $\mathrm{H}$ & G & $F$ & $\mathrm{R}$ & V & V & E & $\mathrm{R}$ & $E$ & $\mathrm{~T}$ & V & V & \\
\hline *001:01 & E & S & S & V & $F$ & $\mathrm{Y}$ & $\mathrm{T}$ & G & $F$ & $\mathrm{R}$ & D & $E$ & $E$ & $\mathrm{~K}$ & $E$ & $\mathrm{R}$ & V & $M$ & \\
\hline${ }^{*} 002: 01$ & $E$ & $S$ & $S$ & V & $F$ & Y & $\mathrm{H}$ & G & $\mathrm{Y}$ & $\mathrm{R}$ & D & $E$ & $\mathrm{R}$ & A & A & $\mathrm{T}$ & Y & V & \\
\hline *005:01 & $E$ & $\mathrm{H}$ & $S$ & L & $Y$ & $Y$ & $Y$ & G & $Y$ & $\mathrm{R}$ & D & $\mathrm{K}$ & $\mathrm{R}$ & $\mathrm{K}$ & $\mathrm{N}$ & $\mathrm{T}$ & $Y$ & V & \\
\hline *013:01 & $E$ & $L$ & $S$ & V & $\mathrm{F}$ & Y & $\mathrm{Y}$ & G & $\mathrm{Y}$ & Q & D & $\mathrm{K}$ & $\mathrm{R}$ & $\mathrm{K}$ & $\mathrm{N}$ & $\mathrm{T}$ & $\mathrm{Y}$ & V & \\
\hline *015:01 & $E$ & S & S & V & Y & $\mathrm{Y}$ & $\mathrm{H}$ & G & $Y$ & $\mathrm{R}$ & V & $\mathrm{K}$ & R & $E$ & $\mathrm{Y}$ & $\mathrm{T}$ & $\mathrm{Y}$ & V & \\
\hline *013:02 & $E$ & L & $S$ & V & $F$ & $S$ & $\mathrm{Y}$ & $\mathrm{D}$ & $Y$ & Q & D & $E$ & $\mathrm{R}$ & $\mathrm{K}$ & $\mathrm{N}$ & $\mathrm{R}$ & Y & V & \\
\hline *014:01:01 & Q & $\mathrm{H}$ & G & V & L & $\mathrm{H}$ & $\mathrm{H}$ & G & $F$ & Q & A & $\mathrm{E}$ & Q & $\mathrm{K}$ & $E$ & $\mathrm{~T}$ & V & V & \\
\hline *010:01 & $E$ & $S$ & $S$ & V & $\mathrm{F}$ & Y & $\mathrm{Y}$ & D & Y & Q & V & $E$ & $\mathrm{R}$ & A & A & $\mathrm{T}$ & Y & G & \\
\hline${ }^{*} 006: 01$ & $E$ & C & $\mathrm{R}$ & V & $\mathrm{L}$ & C & $\mathrm{H}$ & G & $\mathrm{F}$ & $\mathrm{R}$ & V & $E$ & $\mathrm{R}$ & $\mathrm{K}$ & $E$ & $\mathrm{R}$ & V & G & \\
\hline${ }^{*} 012: 01$ & $E$ & $\mathrm{~T}$ & $\mathrm{~K}$ & $\mathrm{~V}$ & $\mathrm{~F}$ & $\bar{Y}$ & $\mathrm{H}$ & G & $\bar{Y}$ & Q & $\mathrm{D}$ & $E$ & $\mathrm{R}$ & $A$ & $A$ & $\mathrm{~T}$ & $\bar{Y}$ & G & \\
\hline${ }^{*} 034: 01$ & E & C & $S$ & V & $\mathrm{F}$ & S & $\mathrm{Y}$ & G & $Y$ & Q & V & $\mathrm{E}$ & Q & $\mathrm{K}$ & $\mathrm{N}$ & $\mathrm{T}$ & $\mathrm{Y}$ & V & \\
\hline *008:01 & E & A & $S$ & V & $\mathrm{F}$ & Y & $\mathrm{Y}$ & G & $F$ & $\mathrm{R}$ & $S$ & $E$ & D & $E$ & $S$ & $\mathrm{R}$ & Y & V & \\
\hline${ }^{*} 020: 01: 02$ & E & C & $\mathrm{R}$ & V & L & $Y$ & $\mathrm{Y}$ & G & $\mathrm{F}$ & $Q$ & $S$ & $E$ & $Q$ & $\mathrm{R}$ & A & $\mathrm{T}$ & Y & V & \\
\hline *016:01 & E & $\mathrm{T}$ & $\mathrm{K}$ & V & $F$ & $Y$ & $\mathrm{~T}$ & G & $Y$ & $\mathrm{R}$ & D & $E$ & E & $\mathrm{K}$ & A & $\mathrm{R}$ & Y & G & \\
\hline${ }^{*} 005: 03$ & E & $S$ & $S$ & L & $Y$ & $Y$ & $Y$ & G & $Y$ & $\mathrm{R}$ & D & $\mathrm{K}$ & R & $\mathrm{K}$ & $\mathrm{N}$ & $\mathrm{T}$ & Y & $\mathrm{F}$ & $>1$ \\
\hline${ }^{*} 005: 02$ & $E$ & $\mathrm{H}$ & $S$ & L & Y & $Y$ & $Y$ & G & $Y$ & $\mathrm{R}$ & D & $\mathrm{K}$ & $\mathrm{R}$ & $\mathrm{K}$ & $\mathrm{N}$ & $\mathrm{T}$ & Y & G & \\
\hline *004:01 & E & $S$ & $S$ & V & $F$ & $Y$ & $\mathrm{~T}$ & G & $F$ & $\mathrm{R}$ & D & $E$ & $\mathrm{R}$ & $E$ & A & $\mathrm{R}$ & Y & V & \\
\hline *005:08 & E & $\mathrm{H}$ & $S$ & V & $Y$ & $Y$ & $\mathrm{H}$ & G & $Y$ & $\mathrm{R}$ & D & $E$ & $\mathrm{R}$ & $\mathrm{K}$ & $\mathrm{N}$ & $\mathrm{T}$ & Y & $\mathrm{F}$ & \\
\hline *038:01 & E & $S$ & $S$ & V & Y & $Y$ & $\mathrm{~T}$ & G & $Y$ & $Q$ & D & $E$ & R & $\mathrm{K}$ & $\mathrm{N}$ & $T$ & $Y$ & V & \\
\hline${ }^{*} 044: 01$ & E & $Y$ & $S$ & V & $F$ & $Y$ & $\mathrm{~T}$ & G & $F$ & $\mathrm{R}$ & D & $\mathrm{K}$ & R & A & A & $T$ & Y & G & \\
\hline
\end{tabular}

B

\begin{tabular}{|c|c|c|c|c|c|c|c|}
\hline Pockets & Amino acid position & Motif & Susceptibility & Asymptomatic & Lymphoma & OR & $p$-value \\
\hline \multirow{4}{*}{4} & \multirow{2}{*}{13,26} & $\mathrm{~K}^{13} \mathrm{~F}^{26}$ & $S$ & 52 & 218 & 2.842 & $<0.00001$ \\
\hline & & $\mathrm{G}^{13} \mathrm{~L}^{26}$ & $\mathrm{R}$ & 36 & 24 & 0.273 & $<0.00001$ \\
\hline & \multirow{2}{*}{$71,74,78$} & $K^{71} A^{74} Y^{78}$ & $S$ & 44 & 198 & 2.953 & $<0.00001$ \\
\hline & & $R^{71} E^{74} V^{78}$ & $\mathrm{R}$ & 45 & 20 & 0.171 & $<0.00001$ \\
\hline \multirow{4}{*}{$1+4$} & \multirow{2}{*}{70,86} & $E^{70} G^{86}$ & $\mathrm{~S}$ & 53 & 200 & 2.362 & $<0.00001$ \\
\hline & & $\mathrm{R}^{70} \mathrm{~V}^{86}$ & $\mathrm{R}$ & 91 & 90 & 0.329 & $<0.00001$ \\
\hline & \multirow{2}{*}{$71,78,86$} & $K^{71} Y^{78} G^{86}$ & $S$ & 45 & 221 & 3.520 & $<0.00001$ \\
\hline & & $R^{71} V^{78} V^{86}$ & $\mathrm{R}$ & 36 & 18 & 0.202 & $<0.00001$ \\
\hline \multirow{2}{*}{6} & \multirow{2}{*}{11,30} & $\mathrm{~T}^{11} \mathrm{Y}^{30}$ & $\mathrm{~S}$ & 52 & 218 & 2.842 & $<0.00001$ \\
\hline & & $\mathrm{H}^{11} \mathrm{H}^{30}$ & $\mathrm{R}$ & 36 & 24 & 0.273 & $<0.00001$ \\
\hline \multirow{2}{*}{7} & \multirow{2}{*}{47,71} & $\mathrm{Y}^{47} \mathrm{~K}^{71}$ & $S$ & 66 & 284 & 3.696 & $<0.00001$ \\
\hline & & $F^{47} R^{71}$ & $\mathrm{R}$ & 39 & 22 & 0.226 & $<0.00001$ \\
\hline \multirow{2}{*}{9} & \multirow{2}{*}{9,57} & $E^{9} D^{57}$ & $\mathrm{~S}$ & 109 & 333 & 2.601 & $<0.00001$ \\
\hline & & $Q^{9} S^{57}$ & $\mathrm{R}$ & 29 & 13 & 0.186 & $<0.00001$ \\
\hline
\end{tabular}

Figure 2. Association of amino acid motifs, which are constituted by antigen recognition sites of peptide-binding pockets in BoLA-DR $\beta$, with lymphoma. (A) Conservation of lymphoma Resistance/Susceptibility amino acid distribution encoded by the Resistance/Susceptibility BoLA-DRB3 allele. * indicates each allele. The order is ranked using Odds ratios (OR) determined in Table 1. BoLA-DRB3 with $\mathrm{OR}<1$ are considered potential resistance alleles, whereas those with OR $>1$ are considered susceptibility alleles. Resistance or susceptibility amino acids are indicated in blue and red, respectively. (B) Association of BLV-induced lymphoma with the combination of amino acid residues. Amino acid combinations and their localizations (pockets) are shown. Resistance amino acid combination: OR $<1$; Susceptibility amino acid combination: OR $>1$. The association study was performed using Fisher's exact test. 


\subsection{D Structure and Electrostatic Charge Analysis of BoLA-DR $\beta$ Binding Pocket}

The electrostatic charge of the MHC binding pocket is reportedly associated with disease susceptibility [32,33]. The underlying mechanism is influenced by the interaction of the MHC binding pocket with specific bound peptides and the subsequent immunoreaction [34]. We investigated the charged potential of resistance and susceptibility BoLA-DR $\beta$ to determine whether electrostatic charged BoLA-DR $\beta$ binding pockets related to BLVinduced lymphoma (Figure 3A). Interestingly, a major charge difference was identified at binding pocket 9 between resistance and susceptibility BoLA-DR $\beta$. A positive electrostatic charge was found in resistance type BoLA-DR $\beta$, BoLA-DRB3 ${ }^{*} 010: 11$ molecule. However, susceptibility BoLA-DR $\beta$ molecules, BoLA-DRB3*005:02 and BoLA-DRB3*016:01, were neutrally charged in binding pocket 9 . These results are in line with the amino acid properties within binding pocket 9 . Negatively charged amino acids, $\mathrm{E}^{9}$ and $\mathrm{D}^{57}$, were found in susceptibility BoLA-DR $\beta$, potentially altering the positively charged environment, resulting in a neutral charged environment (Figure 3B).

A
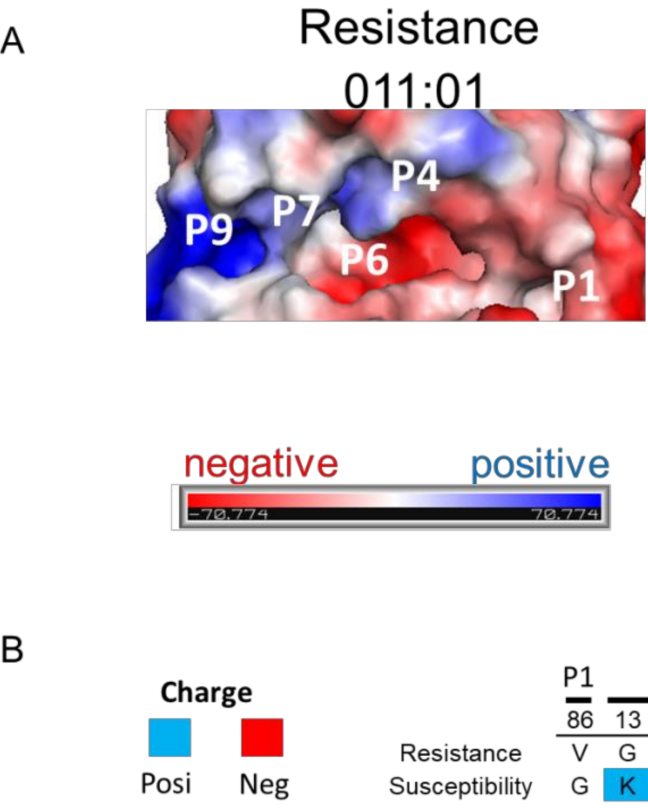

Resistance

B

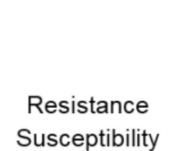

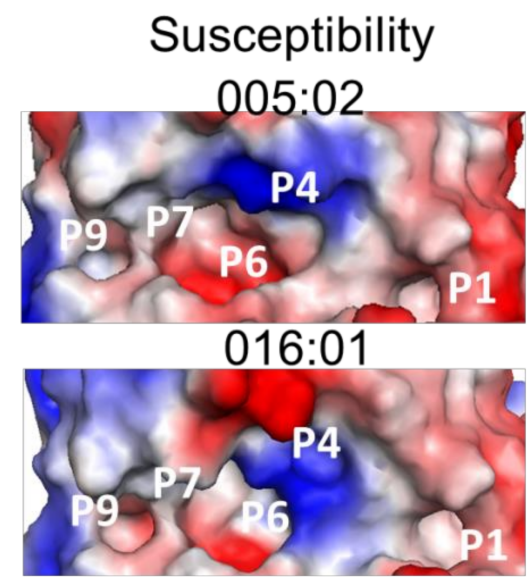

\begin{tabular}{|c|c|c|c|c|c|c|c|c|c|c|c|}
\hline P1 & \multicolumn{5}{|c|}{ P4 } & $P E$ & & \multicolumn{2}{|c|}{ P7 } & \multicolumn{2}{|c|}{ P9 } \\
\hline 86 & $13 \quad 26$ & 70 & 71 & 74 & 78 & 11 & 30 & 47 & 71 & 9 & 57 \\
\hline V & G & $R$ & $\mathrm{R}$ & $E$ & V & * & $\mathrm{H}$ & $F$ & $\mathrm{R}$ & Q & $S$ \\
\hline G & $\mathrm{K}$ & $E$ & $\mathrm{~K}$ & A & $Y$ & $\mathrm{~T}$ & Y & Y & $\mathrm{K}$ & $E$ & D \\
\hline
\end{tabular}

Figure 3. Electrostatic charge differences in binding pockets between lymphoma resistance and susceptibility BoLA-DR $\beta$ molecules. (A) Electrostatic potential of lymphoma resistance BoLA-DR $\beta$ molecule, DRB3*011:01, and susceptibility molecules, $D R B 3^{*} 005: 02$ and $D R B 3^{*} 016: 01$, is shown. Binding pockets 1, 4, 6, 7, and 9 are indicated. Negative charge is indicated in red, and positive charge is indicated in blue. (B) Lymphoma resistance/susceptibility amino acid charges. Positively charged amino acids are indicated with a blue background and negatively charged amino acids are indicated with a red background.

\section{Discussion}

Herein, we report on the first association study between BoLA-DRB3 (BoLA-DR $\beta$ ) polymorphisms with BLV-induced lymphoma in Japanese black cattle at the DNA, amino acid, and electrostatically charged binding pocket levels. Here, DRB3*011:01 was identified as a resistance allele, whereas $D R B 3^{*} 005: 02$ and $D R B 3^{*} 016: 01$ were identified as susceptibility alleles. Interestingly, we demonstrated that antigen recognition sites of BoLA-DR $\beta$ at positions $9,11,13,26,30,47,57,70,71,74,78$, and 86 , as well as the amino acid motifs that covered all peptide-binding pockets, were related to lymphoma susceptibility. Electrostatic charge potential analysis found that pocket 9 of the resistance DRB3*011:01 allele encoding BoLA-DR $\beta$ was positively charged; in contrast, a neutral charge was observed in both $D R B 3^{*} 005: 02$ and $D R B 3^{*} 016: 01$. Our results not only identified BoLA-DRB3 polymorphism susceptibility in Japanese black cattle but contribute to understanding the 
mechanisms underlying how BoLA-DRB3 polymorphisms affect lymphoma susceptibility, thereby providing useful information for future vaccine development.

The association of BoLA-DRB3 polymorphisms to BLV PVL varies in different cattle breeds or regions. Our findings show that, in Japanese black cattle, $D R B 3^{*} 011: 01$ represents a resistance allele with frequency $6.3 \%$, whereas $D R B 3^{*} 005: 02$ and $D R B 3^{*} 016: 01$ represent susceptibility alleles with frequency $3.6 \%$ and $36.3 \%$, respectively, among all allele populations in relation to BLV lymphoma. Previously, we found that DRB3*010:01 and $D R B 3^{*} 011: 01$ were lymphoma resistance alleles, but no susceptibility allele was found in Holstein cows in Japan [19]. In Iranian Holstein cows, BoLA-DRB3*018:02, $D R B 3^{*} 032: 02$, and $D R B 3^{*} 009: 01$ alleles are associated with susceptibility to BLV-induced lymphoma, whereas $D R B 3^{*} 001: 01$ and $D R B 3^{*} 011: 01$ are involved in lymphoma resistance [29]. $D R B 3^{*} 011: 01$ was identified as a resistance allele in all three independent studies; however, other resistance/susceptibility alleles are varied in different cattle breeds or regions. The discrepancies may be due to the allele distribution diversities in different breeds/regions of cattle. For example, the Holstein resistance allele, DRB3*001:01, also showed the resistance tendency in Japanese black cattle but did not reach a significant level, as only few cattle carried this allele in the Japanese cattle population. Furthermore, we did not find any Japanese black cattle harboring the Holstein susceptibility allele BoLA-DRB3 ${ }^{*} 018: 02$, DRB3*032:02, and DRB3*009:01 in the current study. Therefore, association studies should address BoLA-DRB3 polymorphisms and BLV-induced lymphoma in different regions or breeds of cattle.

The BoLA-DR $\beta$ molecule presents a peptide antigen for $\mathrm{T}$ cell recognition and initiates the immune response. There are five binding pockets of BoLA-DR $\beta$, namely, pockets 1,4 , 6,7 , and 9 , responsible for the interaction with the amino acids of antigen peptides at the corresponding positions [35]. These binding pockets shape the species of bound peptide as well as the susceptibility to specific diseases [34-36]. We previously found that amino acids 70 and 71 at pocket 4 of OLA DRB1 related with BLV-induced lymphoma [26]. Animals with the resistance motif at pocket 4 strongly expressed IFN- $\gamma$, which is known as a marker of Th1 response, suggesting the role of binding pocket polymorphisms in the determination of immune responsiveness and BLV-related disease susceptibility [27]. In the current study, in addition to amino acids 70 and 71 at pocket 4 , we found that amino acids $9,11,13,26,30,47$, $57,70,71,74,78$, and 86 , which covered all binding pockets $1,4,6,7$, and 9 , were associated with BLV-induced lymphoma susceptibility. Furthermore, through motif association study, we confirmed that two amino acid motifs: first, 13 and 26, and second, 71, 74, and 78, at pocket 4 were related with lymphoma susceptibility. The correlation was also identified in the amino acid combination of 70 and 86 and 71, 78, and 86 at binding pockets 1 and 4 , respectively. At pocket 6, motif 11 and 30; pocket 7, motif 47 and 71; and pocket 9, motif 9 and 57 were found to be associated with BLV-induced lymphoma. As the susceptibility motifs were found in different binding pockets, it is likely that there is more than a single conserved type of BoLA-DR $\beta$ that could affect BLV-induced lymphoma susceptibility. Besides, the motif patterns which susceptible/resistant to lymphoma development we identified, could contribute to the prediction of susceptibility of some rare alleles, which could not be evaluated in allele association studies owing to their low frequencies. However, whether cattle with these specific motifs could bind with different peptides and induce differential immune responses still requires further investigation.

The electrostatic protein charge affects protein-protein interactions [37]. In the case of MHC, the charge of the MHC binding pocket affects peptide binding preference and therefore influences disease susceptibility. For example, positively charged binding pockets of the HLA-DQ2 molecule promote its ability to accommodate peptides with negatively charged anchor residues compared with other HLA-DQ molecules without positively charged binding pockets [28]. This is a key factor in allowing the HLA-DQ2 molecule to present gluten-derived peptides that are rich in prolines and glutamates [28]. Similarly, HLA-DRB1 polymorphisms lead to differential electrostatic charges of binding pocket 9 and are thus related to the susceptibility to primary sclerosing cholangitis [38]. In this study, 
we found two lymphoma susceptibility molecules, DRB3*005:02 and DRB3*016:01, which were neutrally charged in binding pocket 9; whereas the resistance BoLA-DR $\beta$ molecule, DRB3*011:01, carries a positive charge. This electrostatic charge variation may allow the recognition of different peptide antigens and thus exert a differential immune reaction against BLV-induced lymphoma. Although we found that there were amino acid motifs associated with BLV-induced lymphoma in all binding pockets $(1,4,6,7$, and 9), pocket 9 showed a major difference in electrostatic potential between resistance and susceptibility groups. This result implies that there might be other property differences in addition to that in electrostatic potential, such as in hydrophobicity of binding pockets, that affect BLV-induced lymphoma susceptibility. Interestingly, we found that the BoLA-DRB3*010:01 molecule, which is a lymphoma resistance type identified in Holstein cows, also carries a positive charge in pocket 9 , in line with the current study (data not shown). However, BoLA-DRB3*010:01 was not categorized as a resistance allele in this study, suggesting the possibility of other host factors affecting the susceptibility to BLV-induced lymphoma.

The development of BVL-induced lymphoma is a complex result caused by both viral and host factors in addition to BoLA-DRB3. For example, in the viral factors, BLV provirus integration close to cancer-driver sites or transcriptionally active regions influences host gene expression $[39,40]$. The viral accessory proteins, Tax and G4, are reported as causative agents for cell transformation [41,42]. For host factors, p53 mutation and the polymorphisms of tumor necrosis factor- $\alpha$ are related to lymphoma development [43-45]. Besides, the deregulation of lymphocyte homeostasis, which is characterized by the downregulation of cell turnover rate, is known to lead to leukemia [5,46]. Recently, we found that the expression levels of DNA mismatch repair genes MSH2 and EXO1 were associated with BLV-induced lymphoma, implying that the accumulation of DNA mutations is one of the mechanisms causing disease onset [47]. Furthermore, an arginine-N-methyltransferase, PRMT5, has shown positive correlation with BLV infection with a high pro-viral load and lymphoma stage. Downregulation of PRMT5 expression impaired BLV gene expression and pathogenicity [48]. The factors mentioned above potentially working together with $B o L A-D R B 3$ polymorphisms contribute to BLV-induced lymphoma development.

Taken together, in addition to the BLV-induced lymphoma association study regarding BoLA-DRB3 alleles, amino acid and structure level analyses augment the understanding of how BoLA-DRB3 polymorphisms affect lymphoma susceptibility. These results are not only helpful for cattle breeding selection but for future vaccine development against BLV-induced lymphoma.

\section{Materials and Methods}

\subsection{Sample Collection and Diagnosis}

Blood samples from 106 BLV-infected but clinically normal purebred Japanese black cattle (asymptomatic cattle) and 227 BLV-infected purebred Japanese black cattle with lymphoma (lymphoma cattle) which were selected from a nationwide survey (12 out of 48 prefectures) across Japan were used in this study, and the genomic DNA and plasma from the peripheral blood were isolated. Asymptomatic cattle samples were collected from farms and the infection was confirmed by anti-BLV gp51 ELIAS. Lymphoma cattle samples were collected from slaughterhouses and the infection were confirmed by anti-BLV gp51 ELIAS and some of the sample tested together with southern blotting and PCR of BLV pro-viral genomes. As lymphoma onset in cattle occurs, on average, seven years after BLV infection [49], all asymptomatic cattle were $>9$ years old to reduce the likelihood of collecting potential lymphoma cattle. The age difference between lymphoma and asymptomatic cattle was therefore compensated for further association study. Asymptomatic cattle sample were collected from farms and the subclinical stage of BLV infection was diagnosed according to the lymphocyte count (cells $/ \mu \mathrm{L})$ and the age of each cow $(\leq 5500=$ normal, between 5500 to $7500=$ suspected lymphocytosis and $\geq 7500=$ lymphocytosis). Asymptomatic cattle were defined as BLV-infected but clinically and hematologically normal; PL cattle were defined as BLV-infected but clinically normal cattle with an increase in the 
number of apparently normal B lymphocytes. In this study, only samples from asymptomatic cattle were used for further analysis. This study was approved by the Animal Ethical Committee, and the Animal Care and Use RIKEN Animal Experiments Committee (approval number H29-2-104). Cattle lymphoma status was diagnosed using both gross observation of neoplastic tissues in lymph nodes and histological observation in heart, lung, liver, kidney, spleen, intestines and lymph node in the body. In addition, atypical mononuclear cells in blood sample together with genomic southern blotting for testing disease progression were used for confirmation of some cattle samples [50].

\subsection{BLV Infection Determination Using Enzyme-Linked Immunosorbent Assays (ELISA)}

The anti-BLV gp51 antibody was measured using an anti-BLV antibody ELISA Kit (JNC, Tokyo, Japan), according to the manufacturer's instructions.

\subsection{BoLA-DRB3 Genotyping}

BoLA-DRB3 alleles were determined using the PCR-sequence-based typing (SBT) method, as previously described [51]. Briefly, BoLA-DRB3 exon 2 was amplified via singlestep PCR using the DRB3 forward (5'-CGCTCCTGTGAYCAGATCTATCC- $\left.3^{\prime}\right)$ and reverse $\left(5^{\prime}\right.$-CACCCCCGCGCTCACC-3') primer set. The PCR products were purified using the ExoSAP-IT PCR product purification kit (USB Corp., Cleveland, OH, USA) and then sequenced using the ABI PRISM BigDye1.1 Terminator Cycle Sequencing Ready Reaction Kit (Applied Biosystems, Foster City, CA, USA). The sequence data were then analyzed using Assign 400ATF ver. 1.0.2.41 software (Gonexio Genomics, Fremantle, Australia) to determine the BoLA-DRB3 genotype.

\subsection{Characterization of Amino Acid Properties}

Amino acid charge property of the BoLA-DR $\beta$ binding pocket was characterized according to international ImMunoGeneTics information system [52].

\subsection{3-Dimensional (3D) Protein Structure Modeling of BoLA-DRB3 Molecules}

All BoLA-DRB3 sequences were downloaded from the IPD-MHC database (https: //www.ebi.ac.uk/ipd/mhc/group/BoLA/) (accessed on 4 April 2021). The amino acid sequence alignment was performed using Mega X software [53]. Graphical 3D structures and electrostatic surface potential of BoLA-DRB3 molecules were determined with PyMOL 2.4 (Schrodinger LLC, New York, NY, USA). The structural models of all BoLA-DRB3 molecules were constructed based on the crystal structure of HLA-DRB1: Protein Data Bank (PDB) ID: 1dlh [54].

\subsection{Association Study and Statistical Analysis}

An association study based on Fisher's exact test was performed by comparing the allele, genotype, or amino acid frequencies between asymptomatic and lymphoma cows. The results were penalized with the Bonferroni correction procedure to correct for false positive rate. The alleles or genotypes with odds ratios $(\mathrm{OR})<1$ were categorized as resistance alleles or genotypes. In contrast, those with $\mathrm{OR}>1$ were defined as susceptibility alleles or genotypes. All calculations were performed using Prism 6 (GraphPad, San Diego, CA, USA).

\section{Conclusions}

This is the first report demonstrating the association between BoLA-DRB3 polymorphisms and BLV-induced lymphoma in Japanese black cattle. Through comprehensive analysis of the association at DNA, amino acid, and structure levels, the following three main results were obtained in the present study. First, BoLA-DRB3*011:01 was identified as a lymphoma resistance allele, whereas BoLA-DRB3*005:02 and BoLA-DRB3*016:01 were identified as susceptibility alleles. Second, an amino acid association study indicates that $\mathrm{Q}^{9}, \mathrm{G}^{13}, \mathrm{~L}^{26}, \mathrm{H}^{30}, \mathrm{~F}^{47}, \mathrm{~S}^{57}, \mathrm{R}^{70}, \mathrm{R}^{71}, \mathrm{E}^{74}, \mathrm{~V}^{78}$, and $\mathrm{V}^{86}$ are resistance amino acids; in contrast, 
$\mathrm{E}^{9}, \mathrm{~T}^{11}, \mathrm{~K}^{13}, \mathrm{Y}^{30}, \mathrm{Y}^{47}, \mathrm{D}^{57}, \mathrm{E}^{70}, \mathrm{~K}^{71}, \mathrm{~A}^{74}, \mathrm{Y}^{78}$, and $\mathrm{G}^{86}$ are associated with lymphoma susceptibility. Third, the structure and electrostatic potential modeling shows that the binding pocket 9 of the resistance BoLA-DRB3 molecule is positively charged. Conversely, it is neutrally charged in susceptibility BoLA-DRB3 molecules. Further studies are warranted to determine whether resistance and susceptibility BoLA-DRB3 molecules can bind with different peptide antigens and trigger differential immune responses against BLV and related pathogenesis.

Author Contributions: Conceptualization, Y.A.; Sample collection, E.S., T.F., K.O., Y.A.; Methodology, C.-W.L., S.-n.T. and Y.A.; Software, C.-W.L. and S.-n.T.; Validation, C.-W.L., S.-n.T., and Y.A.; Formal Analysis, C.-W.L., S.-n.T., and Y.A.; Investigation, C.-W.L., S.-n.T., and Y.A.; Resources, S.W., and Y.A.; Data Curation, C.-W.L., S.-n.T., and Y.A.; Writing-Original Draft Preparation, C.-W.L., and Y.A.; Writing-Review and Editing, C.-W.L., S.-n.T., Y.M., H.I., and Y.A.; Visualization, C.-W.L., S.-n.T., and Y.A.; Supervision, Y.A.; Project Administration, Y.A.; Funding Acquisition, Y.A. All authors have read and agreed to the published version of the manuscript.

Funding: This work was supported by Grants-in-Aid for Scientific Research (A (16H02590)) from the Japan Society for the Promotion of Science (JSPS), by the Strategic Improvement project of the national Surveillance and Diagnosis system for Animal (SISDA), and by grants from Livestock Promotional Subsidy from the Japan Racing Association (grant number 30-558).

Institutional Review Board Statement: This study was approved by the Animal Ethical Committee, and the Animal Care and Use RIKEN Animal Experiments Committee (approval number H29-2-104).

Informed Consent Statement: Not applicable.

Data Availability Statement: The data presented in this study are available on request from the corresponding author.

Acknowledgments: The authors thank the veterinary officers of the prefectural Livestock Hygiene Service Centers for their help with blood sampling and the collection of epidemiological data. We also thank all members of the Virus Infectious Disease Field of RIKEN. We are grateful to the Support Unit, Biomaterial Analysis, RIKEN BSI Research Resources Center for helping with the sequence analysis.

Conflicts of Interest: The authors declare no conflict of interest.

\section{References}

1. Underwood, W.J.; Blauwiekel, R.; Delano, M.L.; Gillesby, R.; Mischler, S.A.; Schoell, A. Chapter 15-Biology and diseases of ruminants (sheep, goats, and cattle). In Laboratory Animal Medicine, 3rd ed.; Fox, J.G., Anderson, L.C., Otto, J.M., Eds.; Academic Press: Boston, MA, USA, 2015; pp. 623-694.

2. Aida, Y.; Murakami, H.; Takahashi, M.; Takeshima, S.-N. Mechanisms of pathogenesis induced by bovine leukemia virus as a model for human T-cell leukemia virus. Front. Microbiol. 2013, 4, 328. [CrossRef]

3. OIE. Enzootic bovine leukosis. In OIE Terrestrial Manual World Organisation for Animal Health; OIE: Paris, France, $2012 ;$ pp. 1-11.

4. Bartlett, P.C.; Ruggiero, V.J.; Hutchinson, H.C.; Droscha, C.J.; Norby, B.; Sporer, K.R.B.; Taxis, T.M. Current Developments in the Epidemiology and Control of Enzootic Bovine Leukosis as Caused by Bovine Leukemia Virus. Pathogens 2020, 9, 1058. [CrossRef]

5. Gillet, N.; Florins, A.; Boxus, M.; Burteau, C.; Nigro, A.; Vandermeers, F.; Balon, H.; Bouzar, A.-B.; Defoiche, J.; Burny, A.; et al. Mechanisms of leukemogenesis induced by bovine leukemia virus: Prospects for novel anti-retroviral therapies in human. Retrovirology 2007, 4, 18. [CrossRef] [PubMed]

6. Barez, P.-Y.; De Brogniez, A.; Carpentier, A.; Gazon, H.; Gillet, N.; Gutiérrez, G.; Hamaidia, M.; Jacques, J.-R.; Perike, S.; Neelature Sriramareddy, S.; et al. Recent Advances in BLV Research. Viruses 2015, 7, 6080-6088. [CrossRef] [PubMed]

7. Takeshima, S.-N.; Aida, Y. Structure, function and disease susceptibility of the bovine major histocompatibility complex. Anim. Sci. J. 2006, 77, 138-150. [CrossRef]

8. Aida, Y.; Takeshima, S.N.; Baldwin, C.L.; Kaushik, A.K.; Ruvinsky, A. Bovine immunogenetics. In The Genetics of Cattle; Garrick, D.J., Ruvinsky, A., Eds.; C.A.B. International: Wallingford, UK, 2015.

9. Lei, W.; Liang, Q.; Jing, L.; Wang, C.; Wu, X.; He, H. BoLA-DRB3 gene polymorphism and FMD resistance or susceptibility in Wanbei cattle. Mol. Biol. Rep. 2012, 39, 9203-9209. [CrossRef]

10. Yoshida, T.; Mukoyama, H.; Furuta, H.; Kondo, Y.; Takeshima, S.N.; Aida, Y.; Kosugiyama, M.; Tomogane, H. Association of the amino acid motifs of BoLA-DRB3 alleles with mastitis pathogens in Japanese Holstein cows. Anim. Sci. J. 2009, 80, 510-519. [CrossRef] 
11. Morales, J.P.A.; López-Herrera, A.; Zuluaga, J.E. Association of BoLA DRB3 gene polymorphisms with BoHV-1 infection and zootechnical traits. Open Vet. J. 2020, 10, 331-339. [CrossRef]

12. Takeshima, S.-N.; Ohno, A.; Aida, Y. Bovine leukemia virus proviral load is more strongly associated with bovine major histocompatibility complex class II DRB3 polymorphism than with DQA1 polymorphism in Holstein cow in Japan. Retrovirology 2019, 16, 1-6. [CrossRef]

13. Miyasaka, T.; Takeshima, S.-N.; Jimba, M.; Matsumoto, Y.; Kobayashi, N.; Matsuhashi, T.; Sentsui, H.; Aida, Y. Identification of bovine leukocyte antigen class II haplotypes associated with variations in bovine leukemia virus proviral load in Japanese Black cattle. Tissue Antigens 2012, 81, 72-82. [CrossRef]

14. Udina, I.G.; Karamysheva, E.E.; Turkova, S.O.; Orlova, A.R.; Sulimova, G.E. Genetic mechanisms of resistance and susceptibility to leukemia in Ayrshire and black pied cattle breeds determined by allelic distribution of gene Bola-DRB3. Russ. J. Genet. 2003, 39, 306-317. [CrossRef]

15. Forletti, A.; Lützelschwab, C.M.; Cepeda, R.; Esteban, E.N.; Gutiérrez, S.E. Early events following bovine leukaemia virus infection in calves with different alleles of the major histocompatibility complex DRB3 gene. Vet. Res. 2020, 51, 4. [CrossRef]

16. Jimba, M.; Takeshima, S.N.; Murakami, H.; Kohara, J.; Kobayashi, N.; Matsuhashi, T.; Ohmori, T.; Nunoya, T.; Aida, Y. BLVCoCoMo-qPCR: A useful tool for evaluating bovine leukemia virus infection status. BMC Vet. Res. 2012, 8, 167. [CrossRef]

17. Juliarena, M.A.; Barrios, C.N.; Ceriani, M.C.; Esteban, E.N. Hot topic: Bovine leukemia virus (BLV)-infected cows with low proviral load are not a source of infection for BLV-free cattle. J. Dairy Sci. 2016, 99, 4586-4589. [CrossRef]

18. Lützelschwab, C.M.; Forletti, A.; Cepeda, R.; Esteban, E.N.; Confalonieri, O.; Gutiérrez, S.E. Co-infection with Mycobacterium bovis does not alter the response to bovine leukemia virus in BoLA DRB3*0902, genetically resistant cattle. Res. Vet. Sci. 2016, 109, 10-16. [CrossRef]

19. Lo, C.-W.; Borjigin, L.; Saito, S.; Fukunaga, K.; Saitou, E.; Okazaki, K.; Mizutani, T.; Wada, S.; Takeshima, S.-n.; Aida, Y. BoLA-DRB3 Polymorphism is Associated with Differential Susceptibility to Bovine Leukemia Virus-Induced Lymphoma and Proviral Load. Viruses 2020, 12, 352. [CrossRef]

20. Shen, W.-J.; Zhang, S.; Wong, H.-S. An effective and effecient peptide binding prediction approach for a broad set of HLA-DR molecules based on ordered weighted averaging of binding pocket profiles. Proteome Sci. 2013, 11, S15. [CrossRef]

21. Murray, J.S. How the MHC selects Th1/Th2 immunity. Immunol. Today 1998, 19, 157-162. [CrossRef]

22. Maloy, K.J.; Burkhart, C.; Junt, T.M.; Odermatt, B.; Oxenius, A.; Piali, L.; Zinkernagel, R.M.; Hengartner, H. CD4(+) T cell subsets during virus infection. Protective capacity depends on effector cytokine secretion and on migratory capability. J. Exp. Med. 2000, 191, 2159-2170. [CrossRef]

23. Boasso, A. Type I interferon at the interface of antiviral immunity and immune regulation: The curious case of HIV-1. Scientifica 2013, 2013, 580968. [CrossRef]

24. Sajiki, Y.; Konnai, S.; Okagawa, T.; Maekawa, N.; Nakamura, H.; Kato, Y.; Suzuki, Y.; Murata, S.; Ohashi, K. A TLR7 agonist activates bovine Th1 response and exerts antiviral activity against bovine leukemia virus. Dev. Comp. Immunol. 2021, $114,103847$. [CrossRef]

25. Ohishi, K.; Suzuki, H.; Yasutomi, Y.; Onuma, M.; Okada, K.; Numakunai, S.; Ohshima, K.-I.; Yoji Ikawa, Y.; Sugimoto, M. Augmentation of bovine leukemia virus (BLV)-specific lymphocyte proliferation responses in ruminants by inoculation with BLV ENV-recombinant vaccinia virus: Their role in the suppression of BLV replication. Microbiol. Immunol. 1992, 36, 1317-1323. [CrossRef] [PubMed]

26. Nagaoka, Y.; Kabeya, H.; Onuma, M.; Kasai, N.; Okada, K.; Aida, Y. Ovine MHC class. II. Alleles associated with resistance or susceptibility to development of bovine leukemia virus-induced ovine lymphoma. Cancer Res. 1999, 59, 975. [PubMed]

27. Konnai, S.; Takeshima, S.N.; Tajima, S.; Yin, S.A.; Okada, K.; Onuma, M.; Aida, Y. The influence of ovine MHC Class. II DRB1 alleles on immune response in bovine leukemia virus infection. Microbiol. Immunol. 2003, 47, 223-232. [CrossRef] [PubMed]

28. Jones, E.Y.; Fugger, L.; Strominger, J.L.; Siebold, C. MHC class II proteins and disease: A structural perspective. Nat. Rev. Immunol. 2006, 6, 271-282. [CrossRef] [PubMed]

29. Brujeni, N.G.; Ghorbanpour, R.; Esmailnejad, A. Association of BoLA-DRB3.2 alleles with BLV infection profiles (persistent lymphocytosis/lymphosarcoma) and lymphocyte subsets in iranian holstein cattle. Biochem. Genet. 2016, 54, 194-207. [CrossRef] [PubMed]

30. Bondinas, G.P.; Moustakas, A.K.; Papadopoulos, G.K. The spectrum of HLA-DQ and HLA-DR alleles, 2006: A listing correlating sequence and structure with function. Immunogenetics 2007, 59, 539-553. [CrossRef] [PubMed]

31. Takeshima, S.-N.; Sarai, Y.; Saitou, N.; Aida, Y. MHC class II DR classification based on antigen-binding groove natural selection. Biochem. Biophys. Res. Commun. 2009, 385, 137-142. [CrossRef] [PubMed]

32. Huang, R.; Yin, J.; Chen, Y.; Deng, F.; Chen, J.; Gao, X.; Liu, Z.; Yu, X.; Zheng, J. The amino acid variation within the binding pocket 7 and 9 of HLA-DRB1 molecules are associated with primary Sjögren's syndrome. J. Autoimmun. 2015, 57, 53-59. [CrossRef]

33. Zhang, J.; Chen, Y.; Qi, J.; Gao, F.; Liu, Y.; Liu, J.; Zhou, X.; Kaufman, J.; Xia, C.; Gao, G.F. Narrow groove and restricted anchors of MHC class. I molecule BF2*0401 plus peptide transporter restriction can. explain disease susceptibility of B4 chickens. J. Immunol. 2012, 189, 4478. [CrossRef]

34. Garstka, M.A.; Fish, A.; Celie, P.H.N.; Joosten, R.P.; Janssen, G.M.C.; Berlin, I.; Hoppes, R.; Stadnik, M.; Janssen, L.; Ovaa, H.; et al. The first step of peptide selection in antigen presentation by MHC class I molecules. Proc. Natl. Acad. Sci. USA 2015, $112,1505$. [CrossRef] [PubMed] 
35. Liu, Y.-F.; Lin, C.-Y.; Hong, H.-M. In silico design, synthesis and potency of an epitope-based vaccine against foot-and-mouth disease virus. Int. J. Pharmacol. 2017, 13, 122-133. [CrossRef]

36. Ettinger, R.A.; Papadopoulos, G.K.; Moustakas, A.K.; Nepom, G.T.; Kwok, W.W. Allelic variation in key peptide-binding pockets discriminates between closely related diabetes-protective and diabetes-susceptible alleles. J. Immunol. 2006, 176, 1988. [CrossRef] [PubMed]

37. Zhou, H.-X.; Pang, X. Electrostatic interactions in protein structure, folding, binding, and condensation. Chem. Rev. 2018, 118, 1691-1741. [CrossRef] [PubMed]

38. Donaldson, P.T. Electrostatic modifications of the human leukocyte antigen DR P9 peptide-binding pocket in primary sclerosing cholangitis: Back to the future with human leukocyte antigen DR $\beta$. Hepatology 2011, 53, 1798-1800. [CrossRef]

39. Rosewick, N.; Durkin, K.; Artesi, M.M.; Marçais, A.A.; Hahaut, V.V.; Griebel, P.; Arsic, N.N.; Avettand-Fenoel, V.; Burny, A.; Charlier, C.C.; et al. Cis-perturbation of cancer drivers by the HTLV-1/BLV proviruses is an early determinant of leukemogenesis. Nat. Commun. 2017, 8, 15264. [CrossRef]

40. Gillet, N.A.; Gutiérrez, G.; Rodriguez, S.M.; De Brogniez, A.; Renotte, N.; Alvarez, I.; Trono, K.; Willems, L. Massive depletion of bovine leukemia virus proviral clones located in genomic transcriptionally active sites during primary infection. PLoS Pathog. 2013, 9, e1003687. [CrossRef]

41. Zyrianova, I.M.; Kovalchuk, S.N. Bovine leukemia virus tax gene/Tax protein polymorphism and its relation to Enzootic Bovine Leukosis. Virulence 2020, 11, 80-87. [CrossRef]

42. Willems, L.; Kerkhofs, P.; Dequiedt, F.; Portetelle, D.; Mammerickx, M.; Burny, A.; Kettmann, R. Attenuation of bovine leukemia virus by deletion of R3 and G4 open reading frames. Proc. Natl. Acad. Sci. USA 1994, 91, 11532. [CrossRef]

43. Tajima, S.; Zhuang, W.Z.; Kato, M.V.; Okada, K.; Ikawa, Y.; Aida, Y. Function and conformation of wild-type p53 protein are influenced by mutations in bovine leukemia virus-induced B-cell lymphosarcoma. Virology 1998, 243, 235-246. [CrossRef]

44. Dequiedt, F.; Kettmann, R.; Burny, A.; Willems, L. Mutations in the p53 Tumor-Suppressor Gene Are Frequently Associated with Bovine Leukemia Virus-Induced Leukemogenesis in Cattle but Not in Sheep. Virology 1995, 209, 676-683. [CrossRef]

45. Konnai, S.; Usui, T.; Ikeda, M.; Kohara, J.; Hirata, T.-I.; Okada, K.; Ohashi, K.; Onuma, M. Tumor necrosis factor-alpha genetic polymorphism may contribute to progression of bovine leukemia virus-infection. Microbes Infect. 2006, 8, 2163-2171. [CrossRef]

46. Debacq, C.; Asquith, B.; Reichert, M.; Burny, A.; Kettmann, R.; Willems, L. Reduced Cell Turnover in Bovine LeukemiaVirusInfected, Persistently LymphocytoticCattle. J. Virol. 2003, 77, 13073-13083. [CrossRef]

47. Bai, L.; Hirose, T.; Assi, W.; Wada, S.; Takeshima, S.-N.; Aida, Y. Bovine Leukemia Virus Infection Affects Host Gene Expression Associated with DNA Mismatch Repair. Pathogens 2020, 9, 909. [CrossRef]

48. Assi, W.; Hirose, T.; Wada, S.; Matsuura, R.; Takeshima, S.-N.; Aida, Y. PRMT5 Is Required for Bovine Leukemia Virus Infection In Vivo and Regulates BLV Gene Expression, Syncytium Formation, and Glycosylation In Vitro. Viruses 2020, 12, 650. [CrossRef]

49. Tsutsui, T.; Kobayashi, S.; Hayama, Y.; Yamamoto, T. Fraction of bovine leukemia virus-infected dairy cattle developing enzootic bovine leukosis. Prev. Veter. Med. 2016, 124, 96-101. [CrossRef]

50. Tajima, S.; Ikawa, Y.; Aida, Y. Complete Bovine Leukemia Virus (BLV) Provirus Is Conserved in BLV-Infected Cattle throughout the Course of B-Cell Lymphosarcoma Development. J. Virol. 1998, 72, 7569-7576. [CrossRef]

51. Takeshima, S.-N.; Matsumoto, Y.; Miyasaka, T.; Arainga-Ramirez, M.; Saito, H.; Onuma, M.; Aida, Y. A new method for typing bovine major histocompatibility complex class II DRB3 alleles by combining two established PCR sequence-based techniques. Tissue Antigens 2011, 78, 208-213. [CrossRef]

52. Pommié, C.; Levadoux, S.; Sabatier, R.; Lefranc, G.; Lefranc, M.-P. IMGT standardized criteria for statistical analysis of immunoglobulin V-REGION amino acid properties. J. Mol. Recognit. 2004, 17, 17-32. [CrossRef]

53. Kumar, S.; Stecher, G.; Li, M.; Knyaz, C.; Tamura, K. MEGA X: Molecular evolutionary genetics analysis across computing platforms. Mol. Biol. Evol. 2018, 35, 1547-1549. [CrossRef]

54. Stern, L.J.; Brown, J.H.; Jardetzky, T.S.; Gorga, J.C.; Urban, R.G.; Strominger, J.L.; Wiley, D.C. Crystal structure of the human class II MHC protein HLA-DR1 complexed with an influenza virus peptide. Nat. Cell Biol. 1994, 368, 215-221. [CrossRef] [PubMed] 